\title{
اثر التفكير السياسي لصانع القرار في تحليل البيئة الاستراتيجية للدولة (دراسة تطبيقية في وزارة المالية العراقية)
}

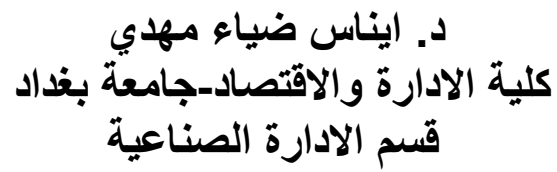

\section{ABSTRUCT}

The Political Thinking Regarded as an important element for the formulation of the stat, weather in its formation, the structure of it s entity, its political system and it $s$ governmental instruments .The political thinking can not act without determined strategy, So they intend to work hard to formulate a railed strategy that make them able to determine its directions to general issues.

The Study aimed to solve the problem through the following question:

1- What are the levels of Political Thinking and Strategic Analysis in the financial ministry?

2- What are the relation ship between the dimensions of Political Thinking and the stages of Strategic Analysis?

3- what is the influence of the dimensions of Political Thinking and Strategic Analysis in the financial ministry?

4- What are the differences among the financial ministry partiers in the dimensions of Political Thinking and Strategic Analysis?

The executive managers of the financial ministry regarded as a sample for the research .The questionnaire used to collect the necessary data the research needs. That data has been analyzed by statistical methods, and proved the rightful of the supposed model.

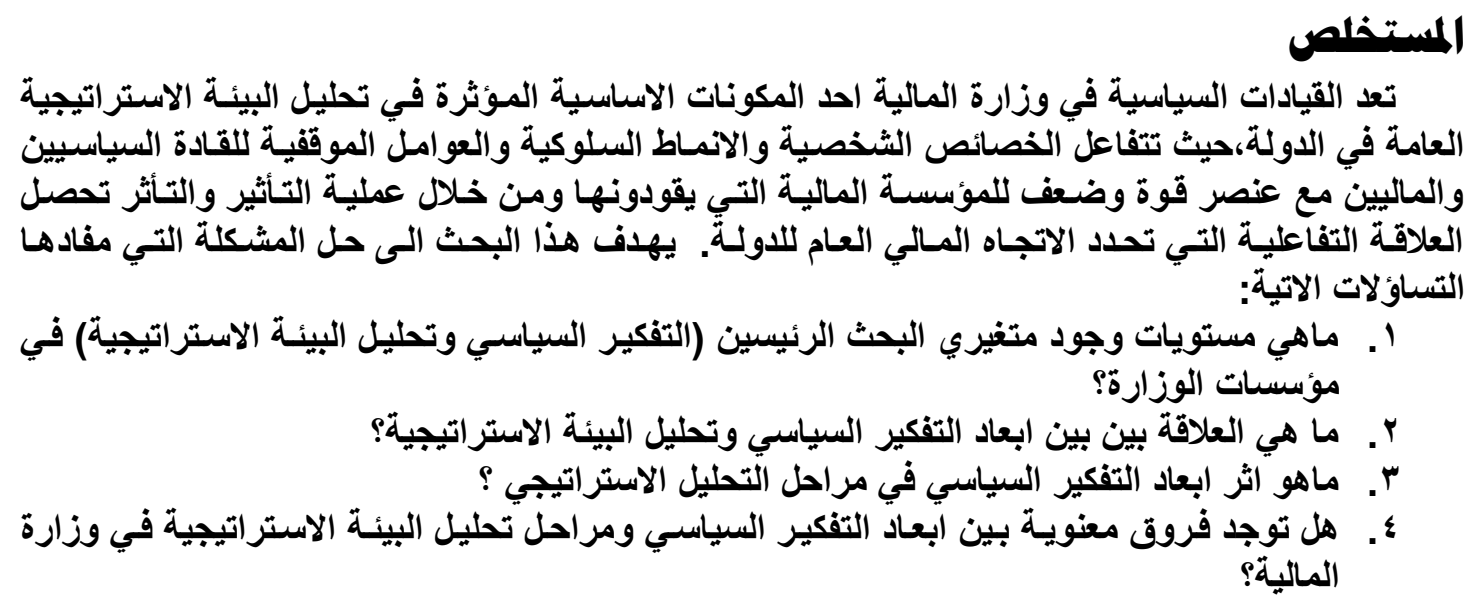


(دهراسة تطبيقة فُونهاسةالماليةالهـاقية)

لقد بني البحث على افترض علمي مفاده (وجود اثر لابعاد التفكير السياسي في تحليل البيئة الستراتيجية)

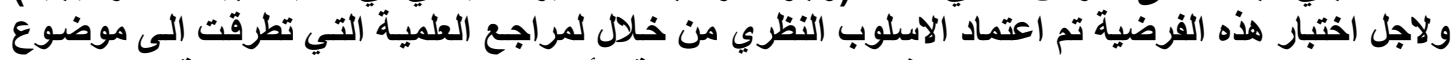

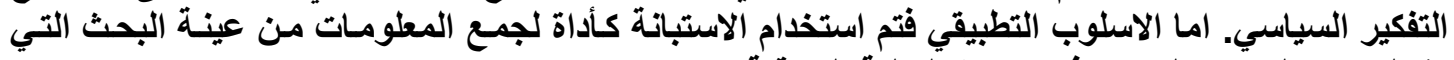
تثكلت من المدراء العامين في وزارة اللمالية العراقية.

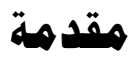

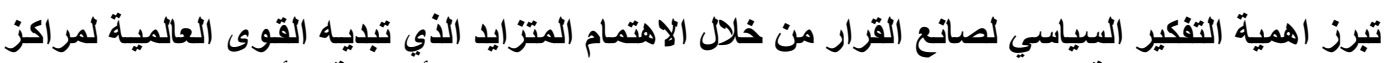

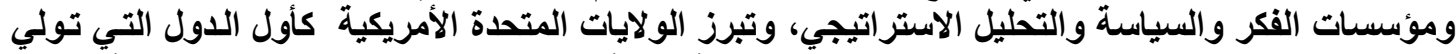

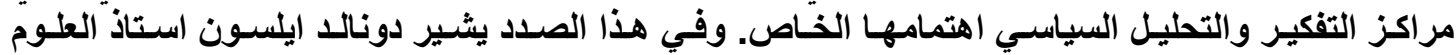

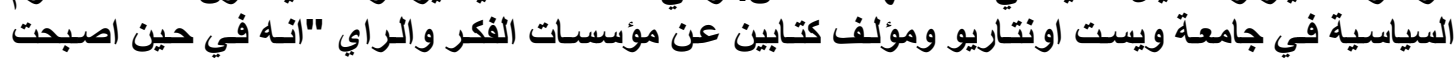

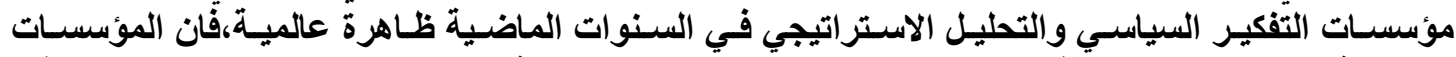

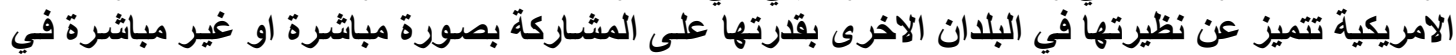

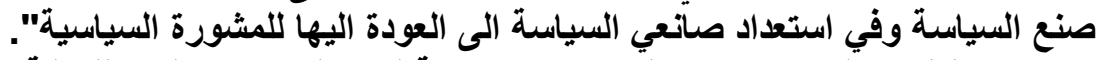

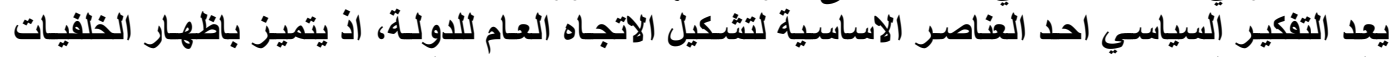

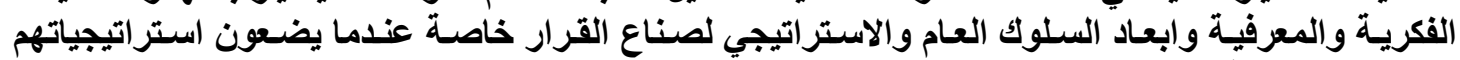

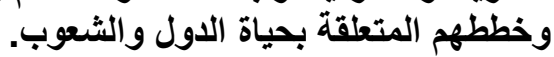

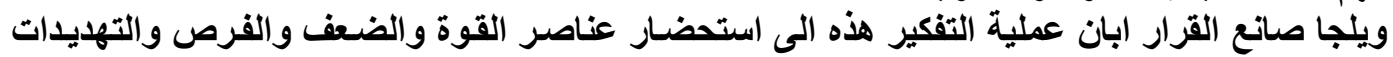

التي تحيط دولته، وهو ما يطلق علية عملية تحليل البيئة الاستراتيجية للاولة ومكوناتها علئ الرئيسية.

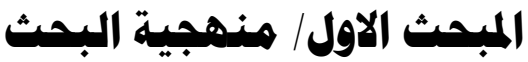

\section{هشكلة البهث}

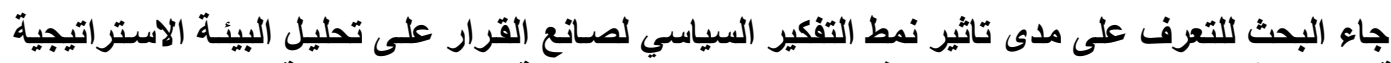

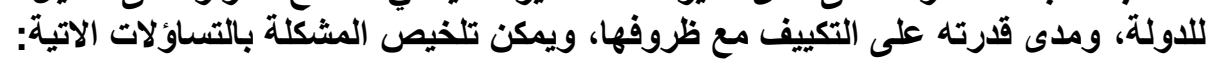
ما مدى وضوح مفهوم التفكير السياسي. -

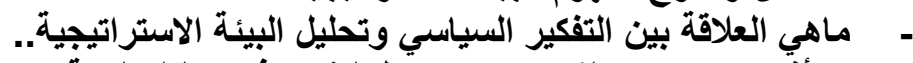

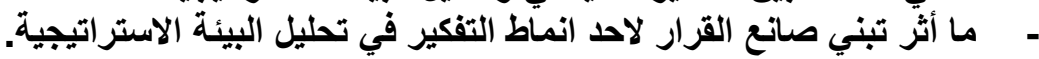

\section{اهداف البحث}

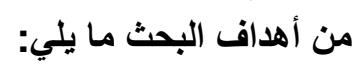

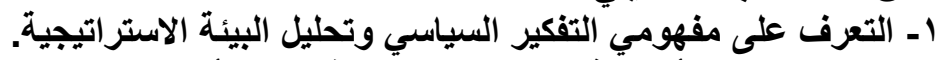

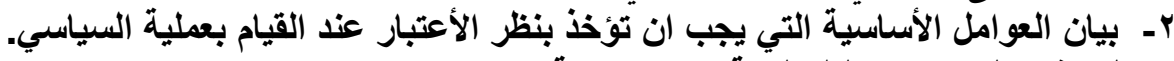

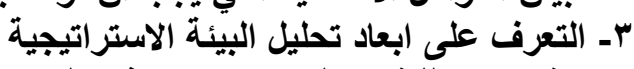

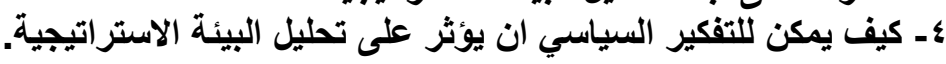

\section{هنههج البحث وادواته}

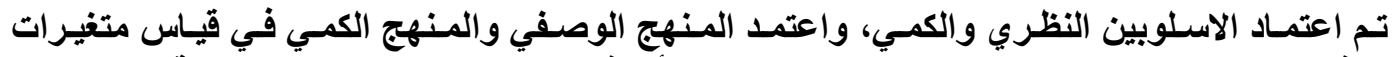

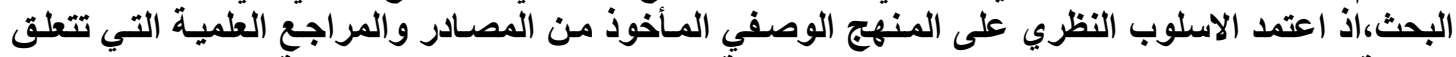

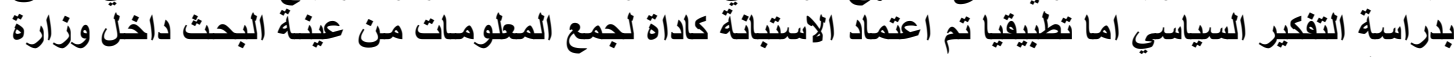

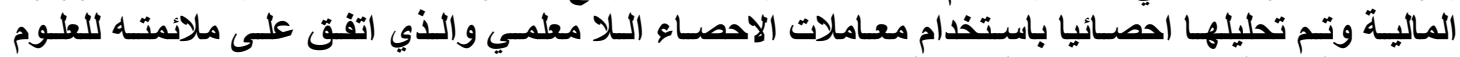
الاجتماعية عامة والعلوم السياسية خاصة. 
(دمراسة تطبيقة فئوناسةالماليةالعـاقية)

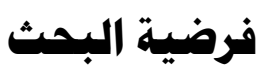

لقد بني البحث على الفرضيات الاتية:

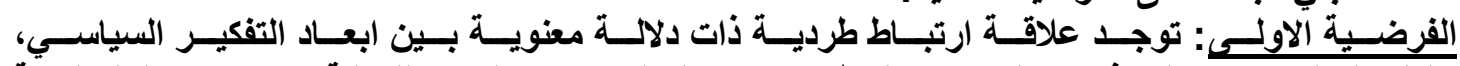

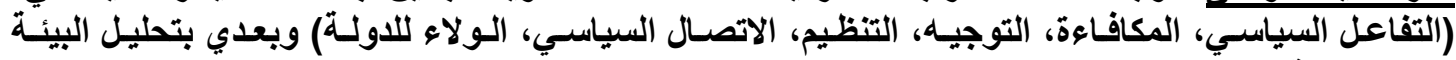
الاستراتيجية . الفرضية الثثانية: يوجد اثر ذو دلائة معنوية لابعاد التفكير السياسي، (التفاعل السياسي، المكافاءة، التوجيه،

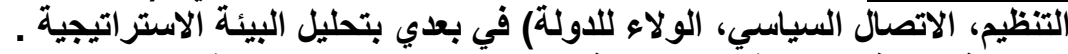

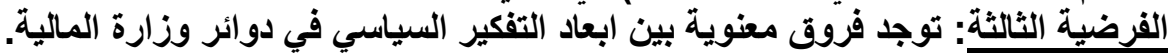

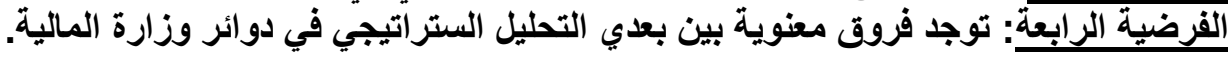

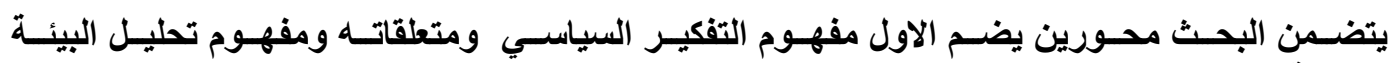

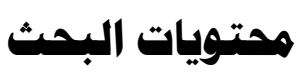

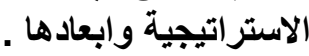

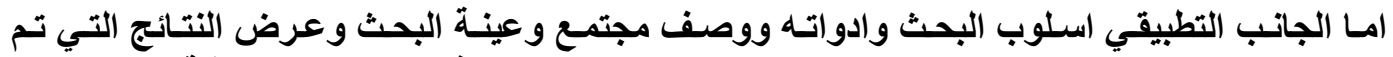

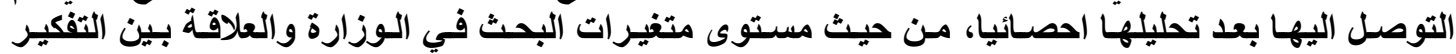

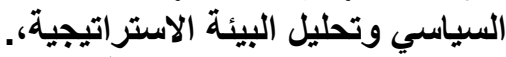
وتم التوصل الى مجموعة الينة الاستئتناجات والتوصيات كما سيتبين لاحقا.

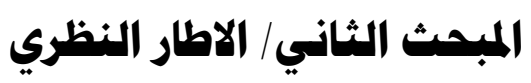

\section{اولا: هفهوم التفكير السياسي .}

يختلف ظهور مصطلح التفكير السياسي (POLITICAL THINKING) في الاراسة عن الاستي الاستخدام

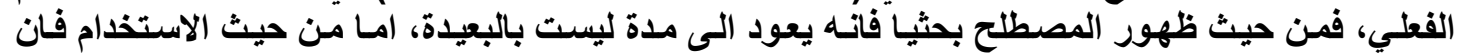

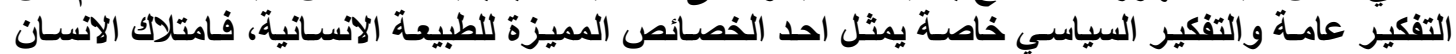

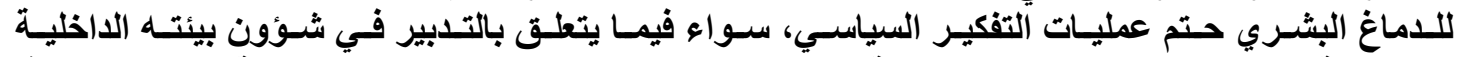

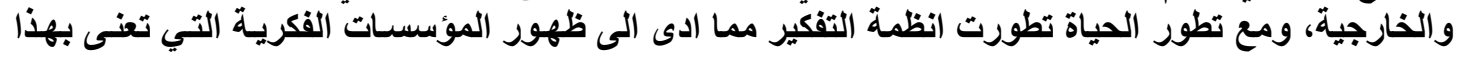

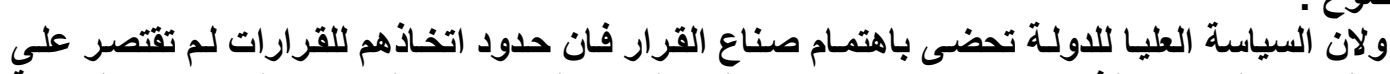

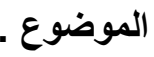

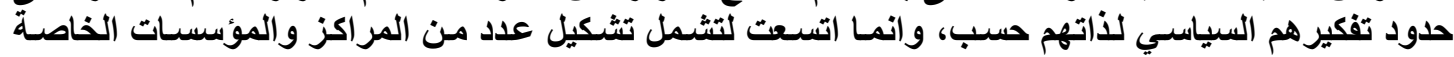

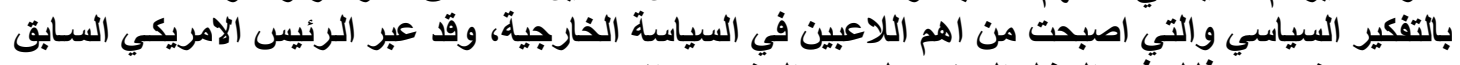

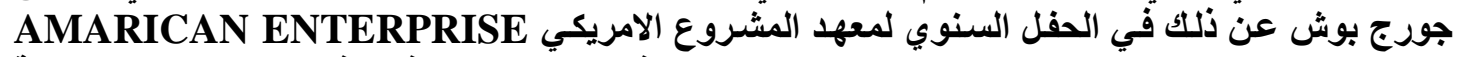
INSTITUTE

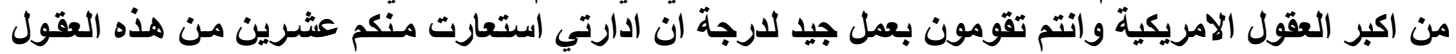

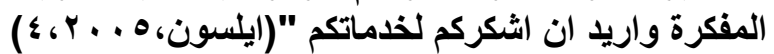

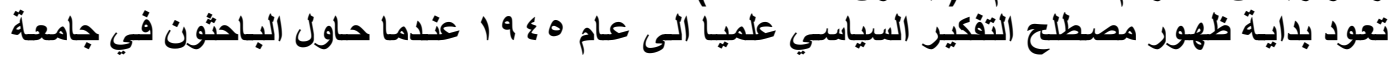

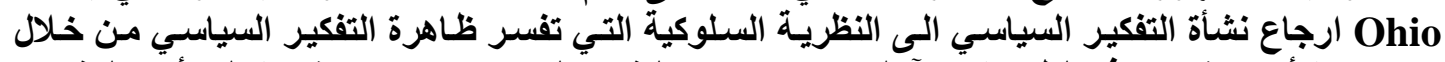

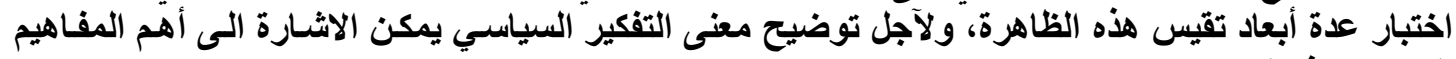




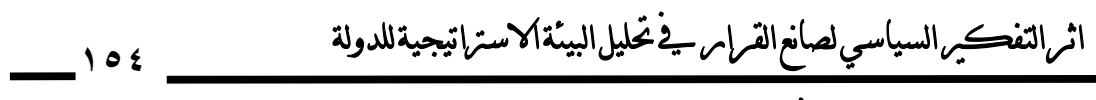

(دهراسة تطبيقة فُونهاسةالماليةالهـاقية)

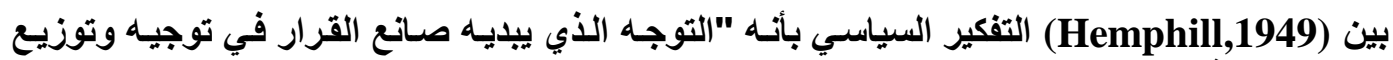

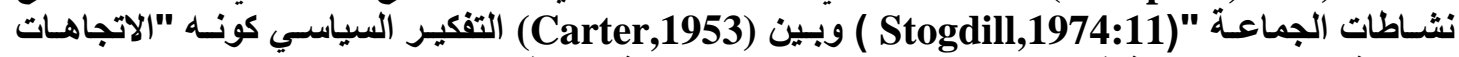

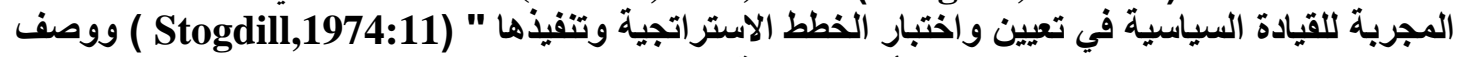
(Fiedler,1967:8)

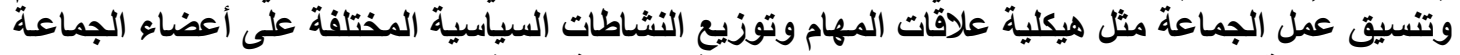

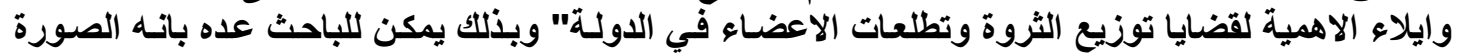

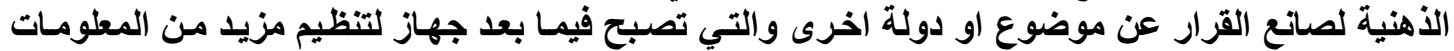

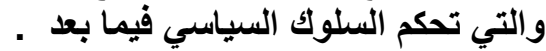

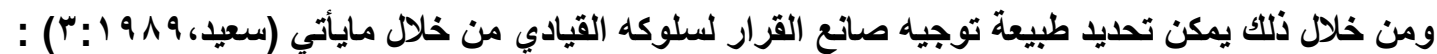

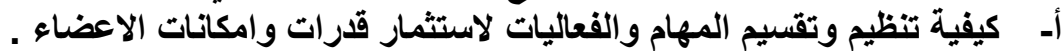

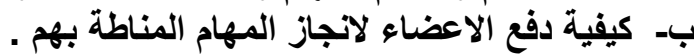

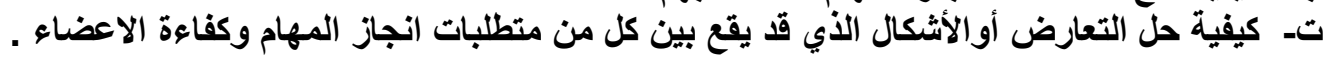

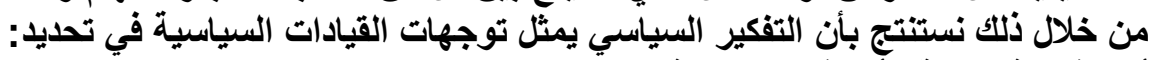
أ- فلسفة الدولة وأهدافها المرحلية.

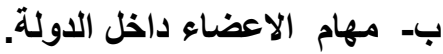
ج- الحالة المستقبلية التي تطمح الأولة للوصلة اللوصول اليها.

\section{ثانيا: انهاط التفكير السياسي}

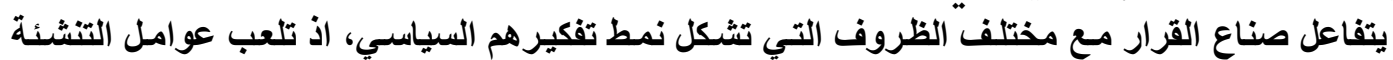

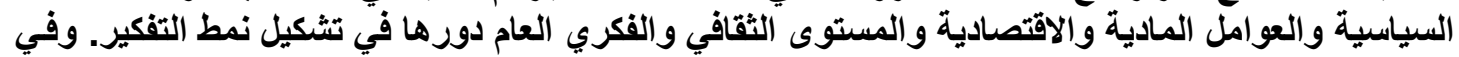

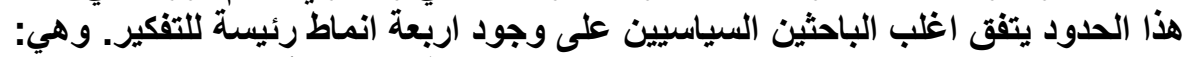

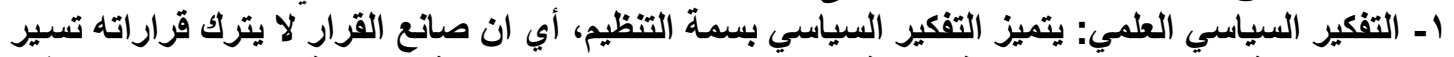

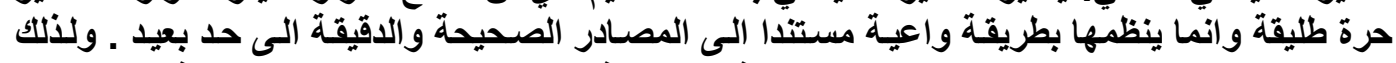

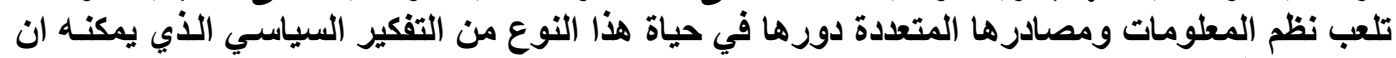

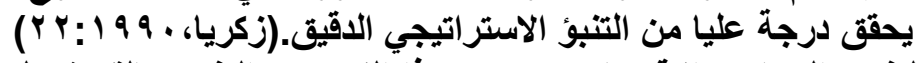

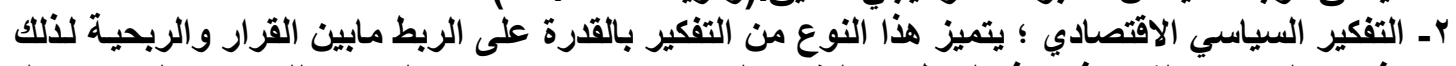

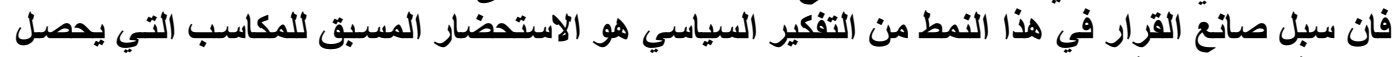
عليها في حال اتخاذه لقرار معين.

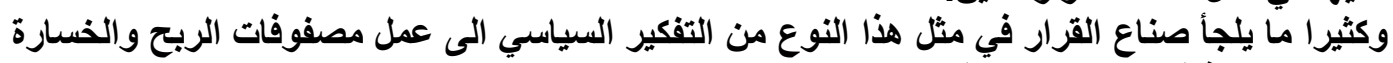

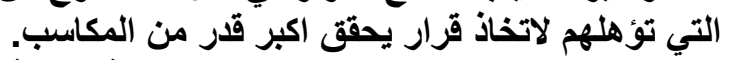

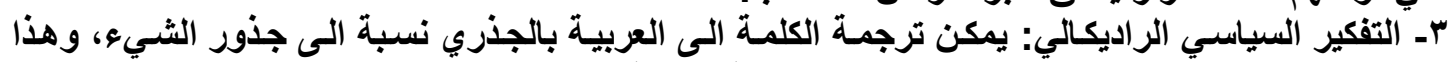

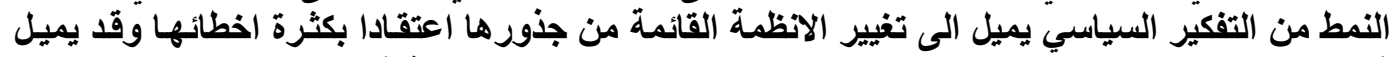

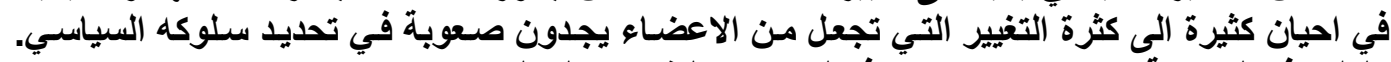

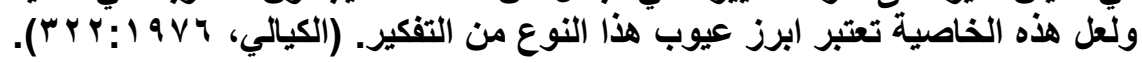

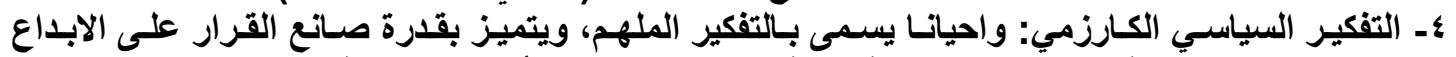

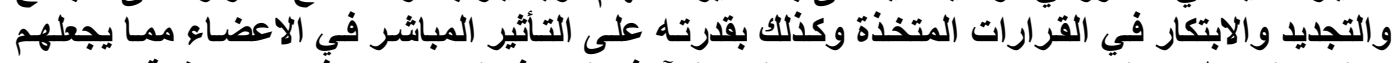

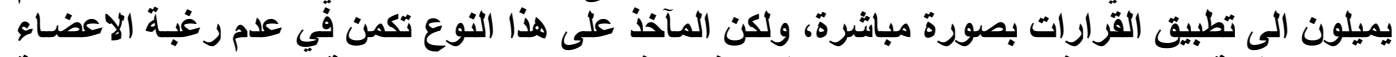

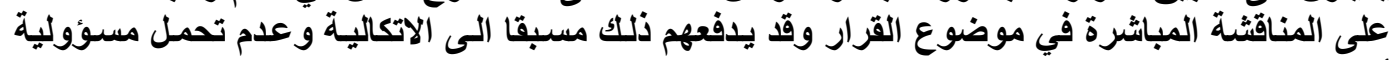

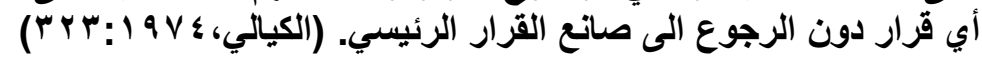




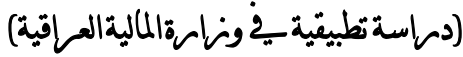

\section{ثالثا: قياس التفكير السياسي لصانع القرار}

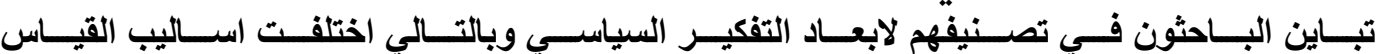

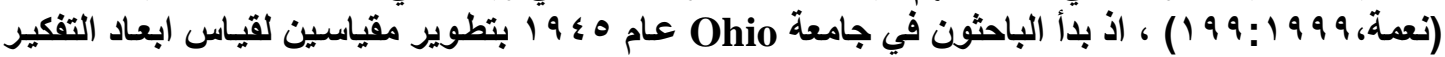

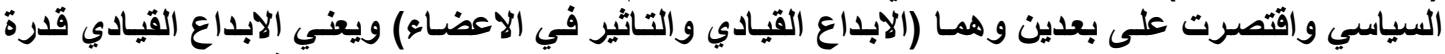

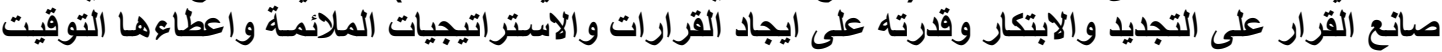

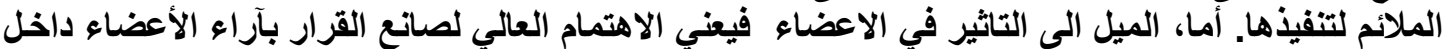

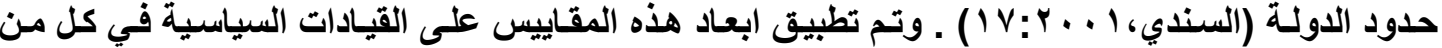

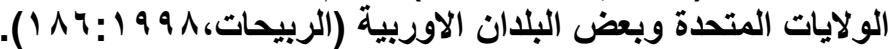

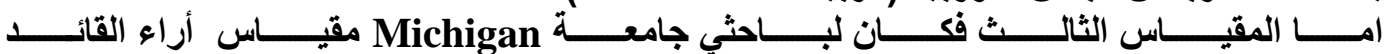
Leader Opinions Questionnaire

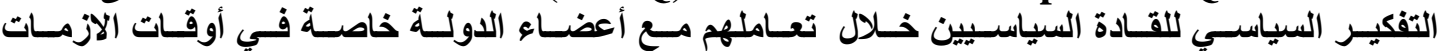

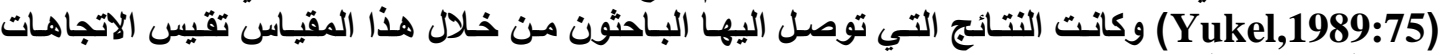

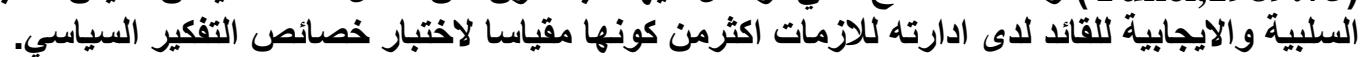

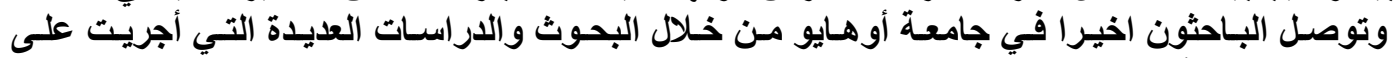

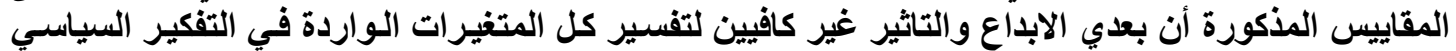

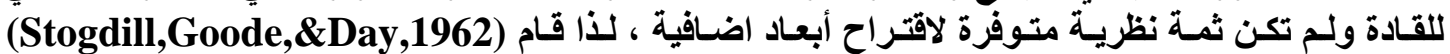

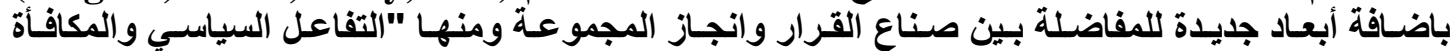
والتظيم والتوجيه والاتصال السياسي والولاء للاولة "(Yukel,1989:75) )ويمكن توضيح مفاهيم الابعاد

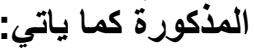

اــ التفاعل السياسي: ويتمثل باسلوب عمل صانع القرار ضمن بيئته المفعمة بالمتفيرات السياسية المختلفة.

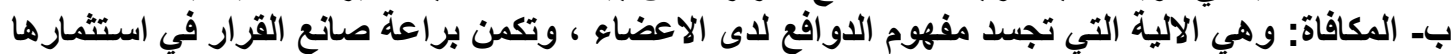

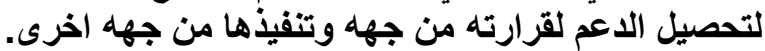

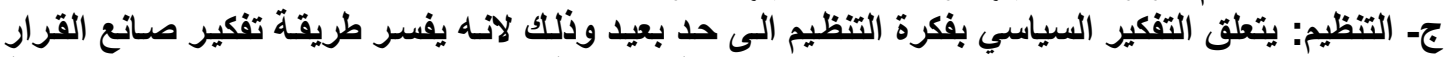

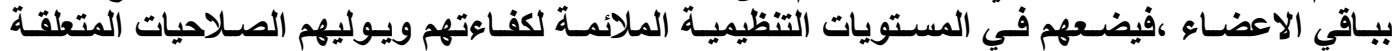

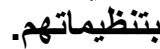

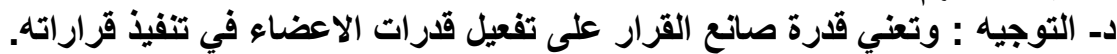

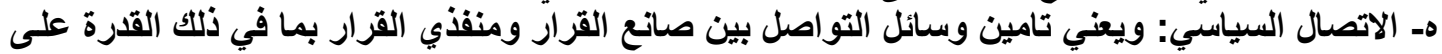

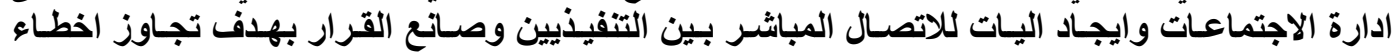

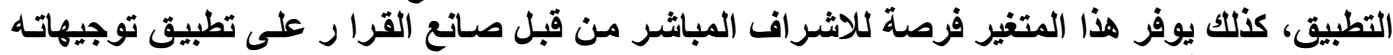
بصورة صحيحة. وـ الولاء للاولـة: ان التفكير السياسـي الذي يهدف الـى تحقيق المكاسب للاولـة يمكن ان نعده احـ الاوجـه المهمة لولاء صانع القرار للاولة. 
(دهراسة تطبيقة فُونهاسةالماليةالهـاقية)

\section{رابعا: هفهوم التصليل الاستراتيجي:}

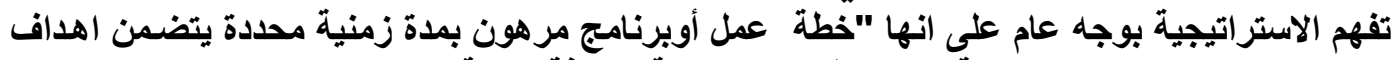

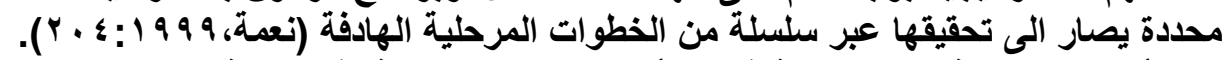

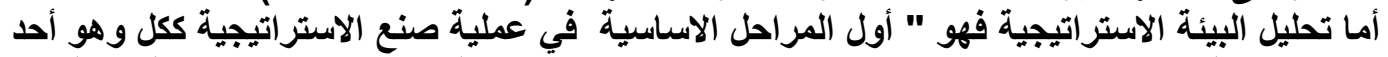

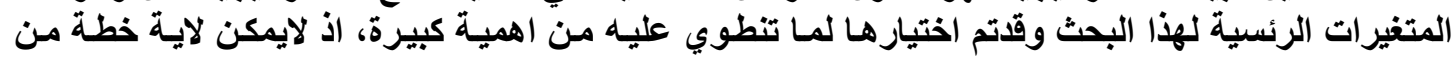

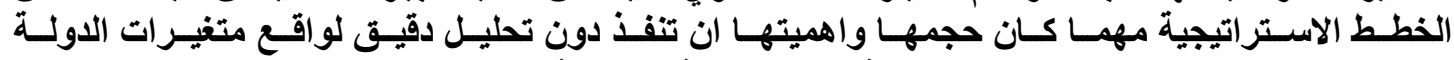

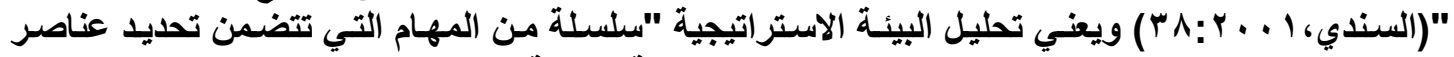

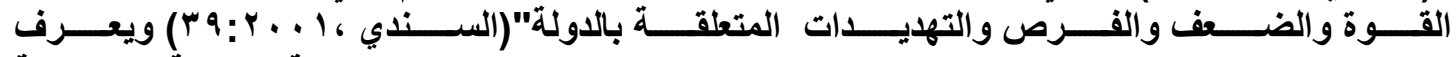
(بheelen \&Hunger)

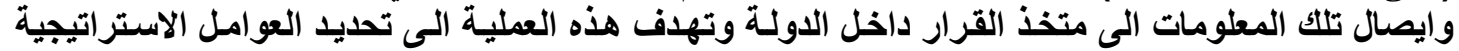

التي تساهم في تحديد مستقبل الدولئ.

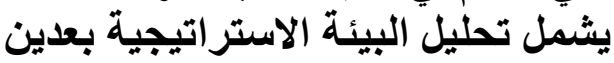

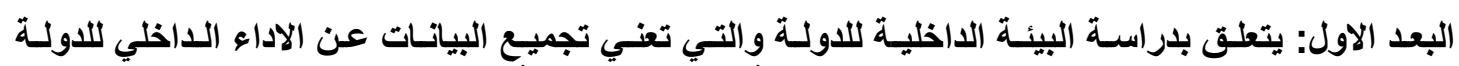

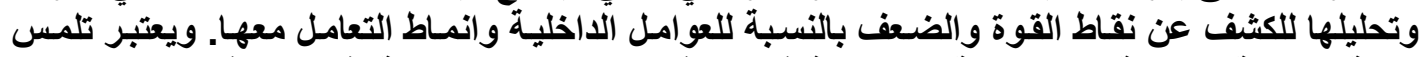

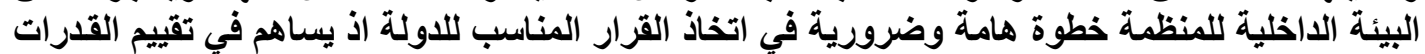

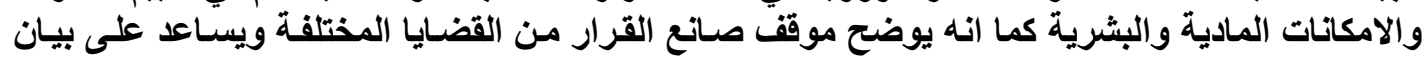

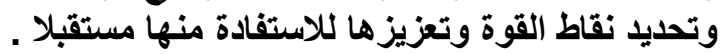

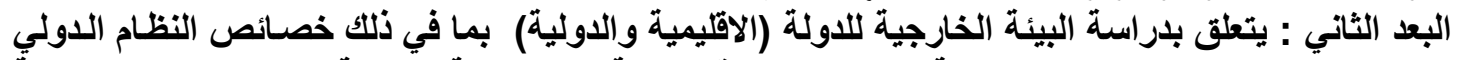

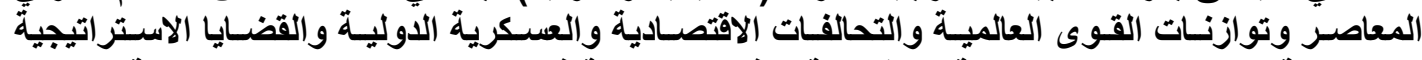

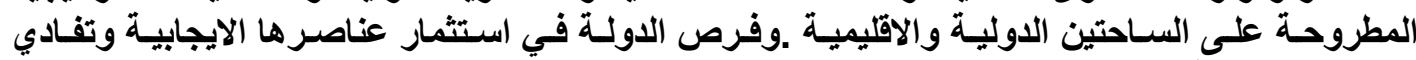

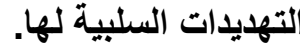

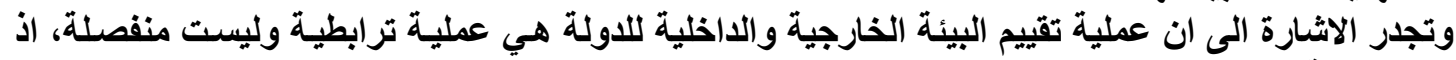

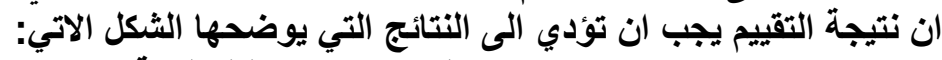
شكل (1) ابعاد تحليل البيئة الاستراتيجية الأية نقاط الضعف فئف فرص تهديد نقاط القوة يتضح من الثكل السـابق ان تحليل البيئة الاستراتيجية هي خطوة هامـة في اتخـاذ القرار والتي يمكن

\begin{tabular}{|c|c|}
\hline نقاط ضعف تحول دون استثمار الفرص & نقاط قوة يمكن استخدامها في استثمار الفرص \\
\hline نقاط ضعف تسبب تهديدات خارجية & نقاط قوة تستخدم لمواجهة التهديدات \\
\hline
\end{tabular}


(دراسة تطبيقية ئوناسةالماليةالماقية)

\section{خاهسا: هراحل التهليل الاستراتيجي}

تسعى الدول عبر خبراء صناعة القرار الى تحليل بيئتها الاستراتيجية بهدف الوقوف على على اهم العوامل

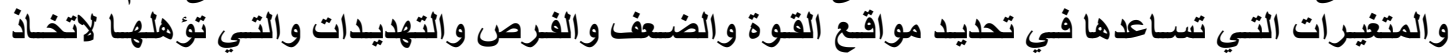

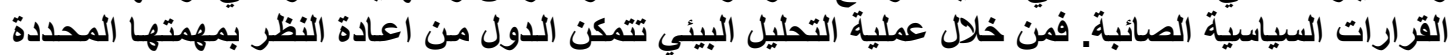

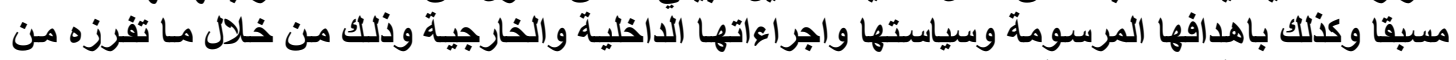

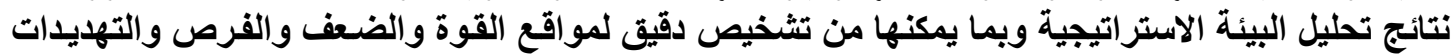

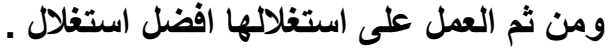

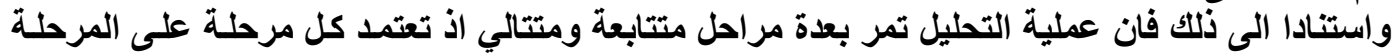
السابقة لها، كما ياتي (Grindly:1983) نقلا عن (Noraynan\&Faha,1982:25)

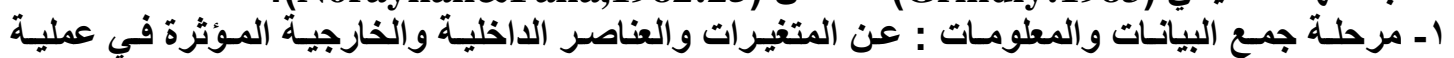

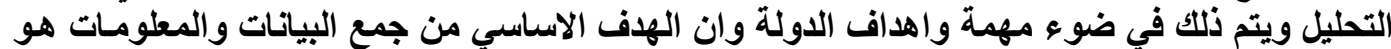

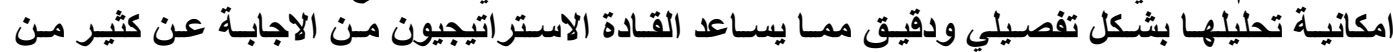

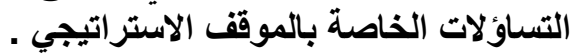

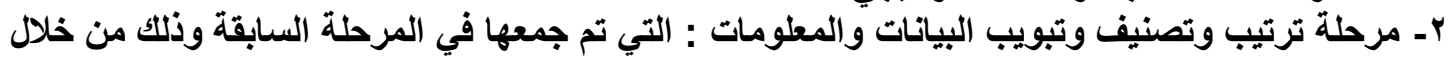

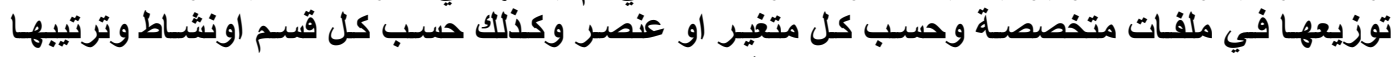

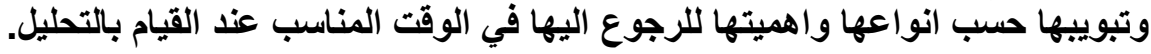

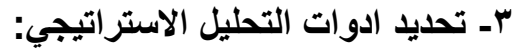
تعيين أدوات التحليل من خطط عناصر و استحضار الاعتبارات المؤثرة في عملية التحليل الاستراتيجي.

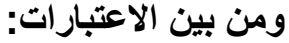

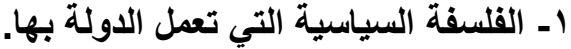

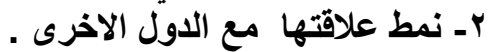

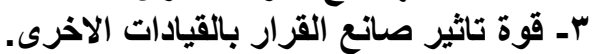

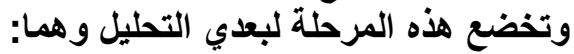

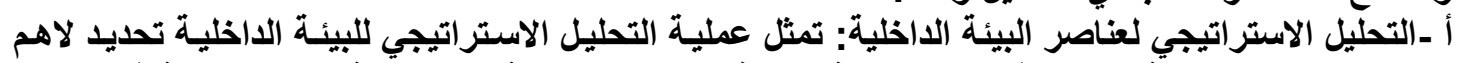

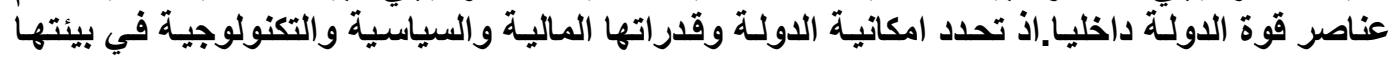

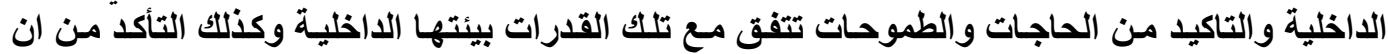

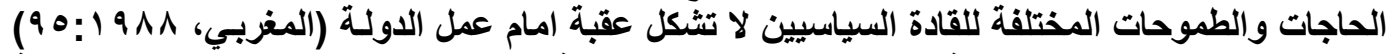

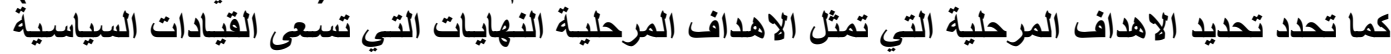

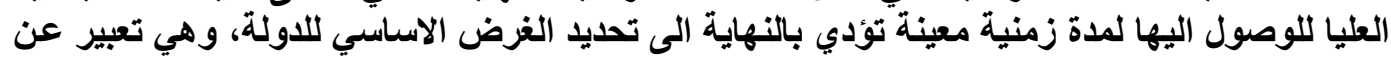

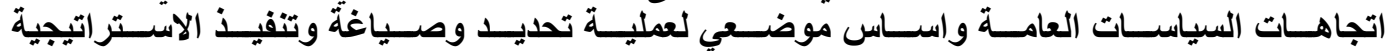

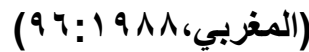

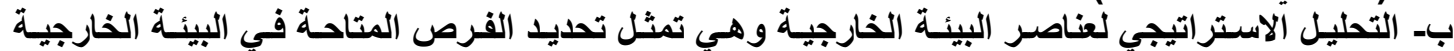

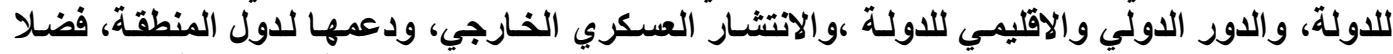

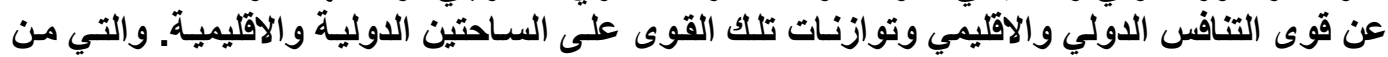

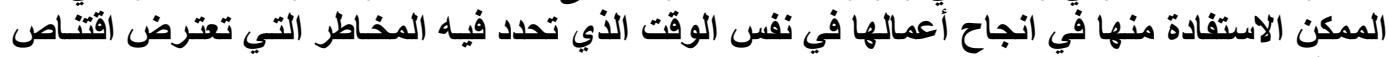




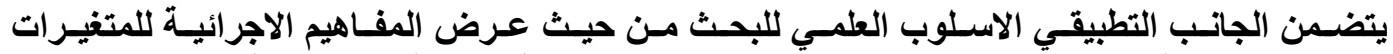

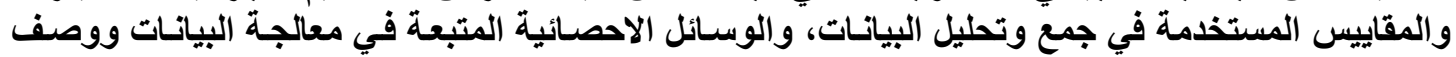

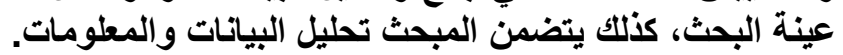

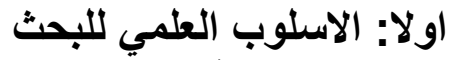
تستعرض هذه الفقرة كل من المفاهيم الاجرائية التي تم على التئ اساسـها اختيار استبانة البحث، وكذلك يتم

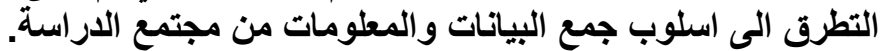

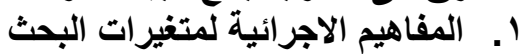

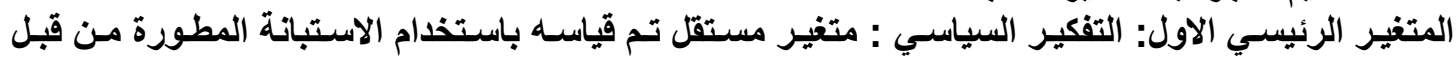
الئو Hemphill

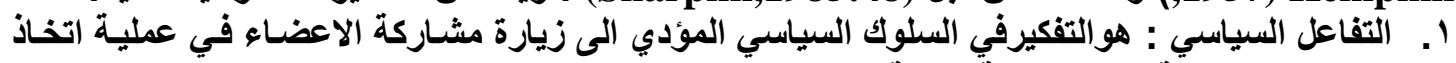

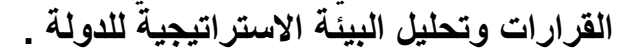

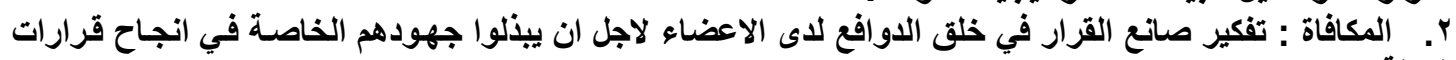

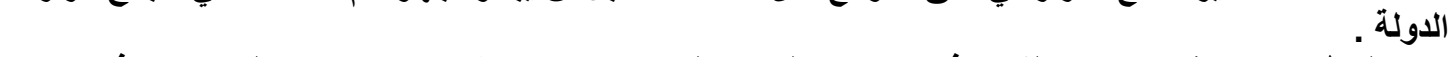
rا. التظيم: و هو تفكير صـانع القرار في ترتيب اولويات المهام وتحديد صلاحيات الاعضساء السياسيين في ميدان

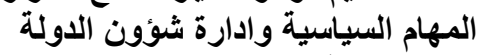

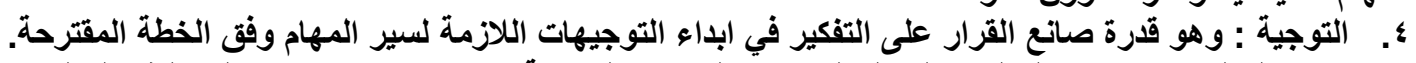

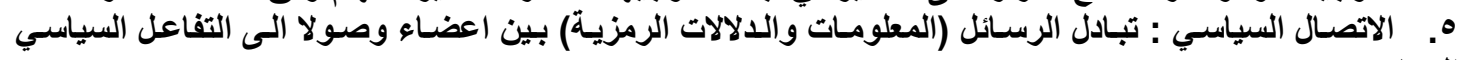

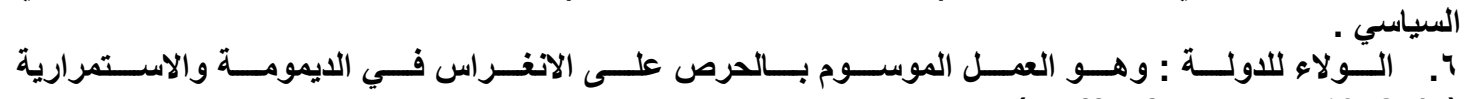
.(Hoffer\&schendel,1978:47) المتغير الرئيسي الثاني (التحليل الاستراتيجي) : تم اعتماد استبانة خاصة لقياسه تعتمد على تحديد بعدي تحليل التيل البيئة

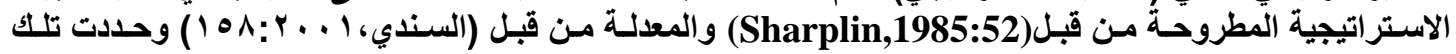

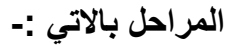

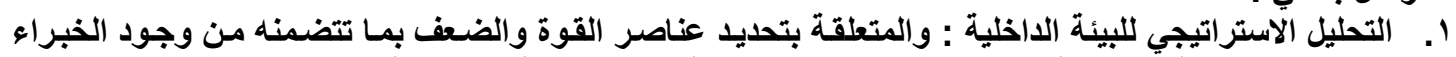

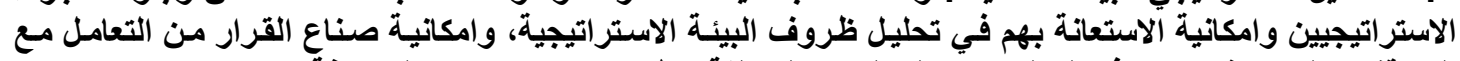

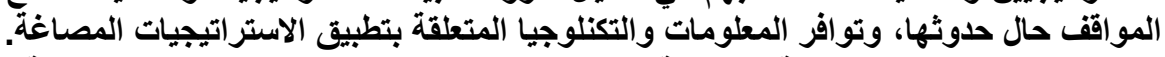

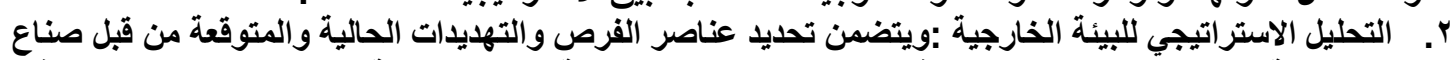

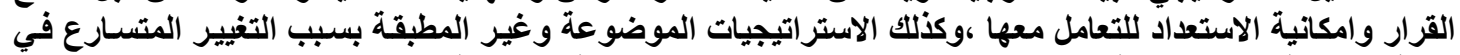

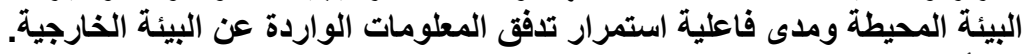
r- أساليب جمع وتحليل البيل البيانات

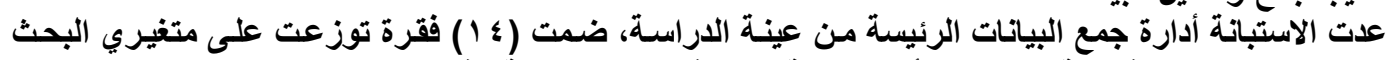

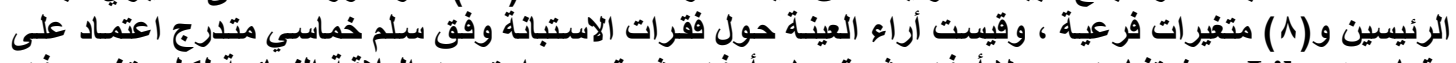

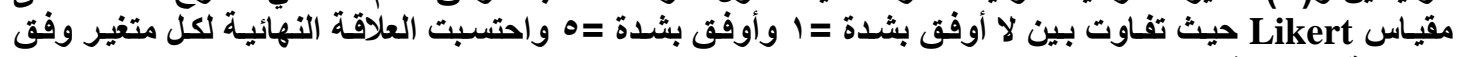

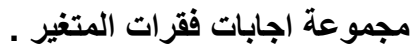

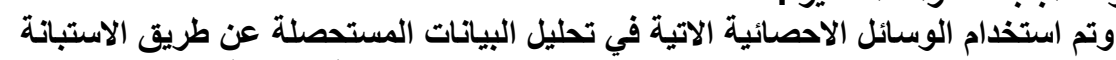

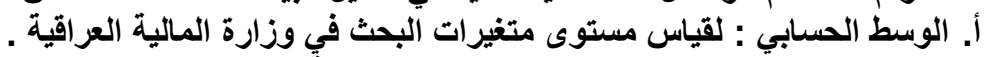

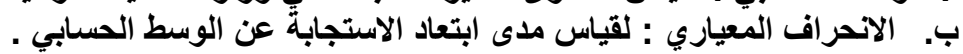

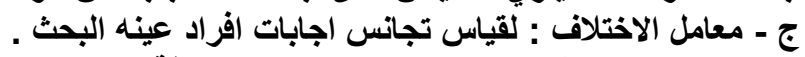

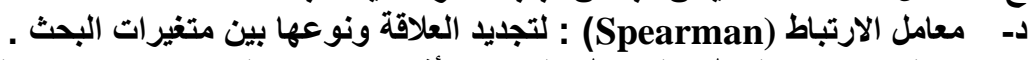

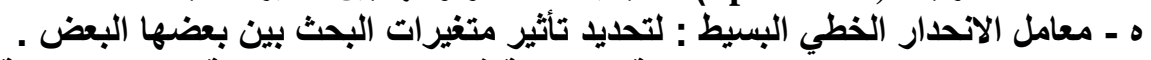

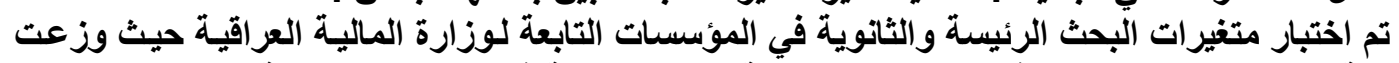

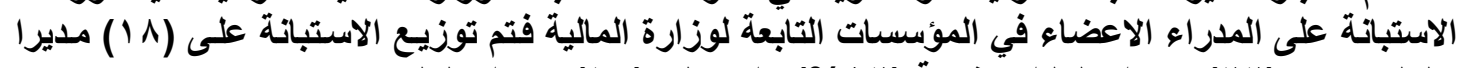

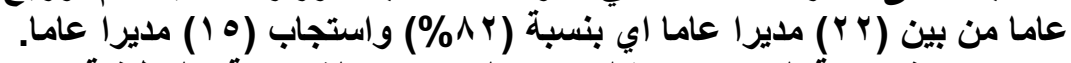

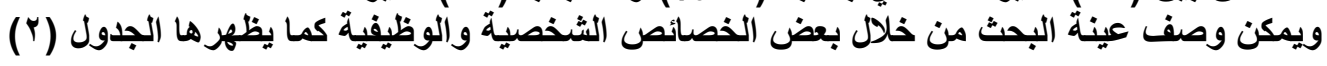




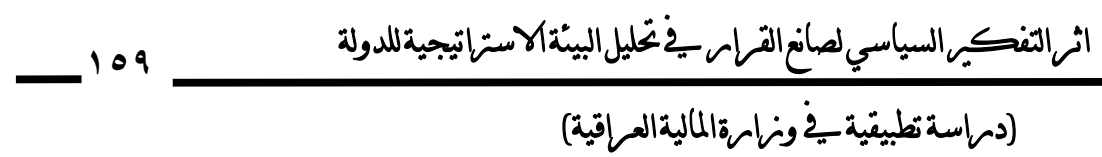

جدول (r) وصف عينة البحث

\begin{tabular}{|c|c|c|}
\hline عينة البحث & \multicolumn{2}{|c|}{ الخصنص الخص } \\
\hline 10 & ذكر & \multirow[t]{2}{*}{ الجنس الجن } \\
\hline- & أنثى & \\
\hline 10 & متزوج & \multirow[t]{2}{*}{ ل الحالة الاجتماعية } \\
\hline - & 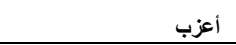 & \\
\hline 1 & لايوجد & \multirow{4}{*}{ عدد الاطفال } \\
\hline r & $r-1$ & \\
\hline v & $\varepsilon_{-} r$ & \\
\hline . & 8.0 & \\
\hline r & ؛ & \multirow{4}{*}{ لعر } \\
\hline$r$ & $0 . . .44$ & \\
\hline$r$ & 00.01 & \\
\hline$\wedge$ & به به فاكثر & \\
\hline 1 & r...10 & \multirow{5}{*}{ مدة المهام في مؤسسات الدولة } \\
\hline 1 & ro-ri & \\
\hline$\varepsilon$ & r...ru & \\
\hline$\varepsilon$ & ro-mi & \\
\hline . & ب ب فاكثر & \\
\hline$\varepsilon$ & $0 .-1$ & \multirow{5}{*}{ الددة التي قضاها كدير عام } \\
\hline$\varepsilon$ & A.- & \\
\hline$r$ & rr-9 & \\
\hline 1 & 19.15 & \\
\hline$r$ & 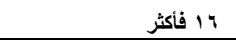 & \\
\hline v & بكلوريوس & \multirow{4}{*}{ الشهادة الجامعة } \\
\hline 1 & ماجستير & \\
\hline . & دكتوراه & \\
\hline r & دبلوم عالي & \\
\hline ir & لـ العراق & \multirow{3}{*}{ اللاولة المانحة للشهادة } \\
\hline 1 & الولايات المتحدة الاهريكية & \\
\hline 1 & رومانيا | روبا & \\
\hline
\end{tabular}




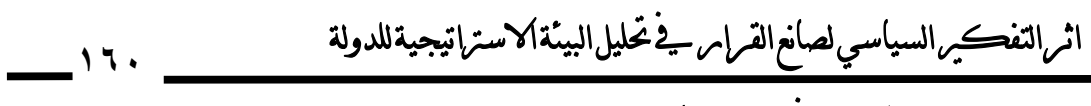

(دهراسة تطبيقة فُونهاسةالماليةالهـاقية)

ثانيا: تهليل البيانات والمعلوهات

1- مستوى وجود متغيرات البحث

يمكن متابعة مستوى وجود متغيرات البحث البحث الرئيسي (التفكير السياسي وتحليل البيئة الاستراتيجية) في وزارة المالية من خلال الفقرات الأتية:

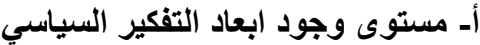

يمكن توضيح مستوى ابعاد التفكير اللياسي في مؤسسات وزارة المالية من خلال الجدول (r) .

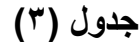
الوسط الحسابي والاتحراف المعياري ومعامل الاختلاف لأبعاد التفكير السياسي في وزارة المالية

\begin{tabular}{|c|c|c|c|}
\hline معامل الاختلاف & الانحراف المعياري & الوسط الحسابي & ابعاد التفكير السياسي \\
\hline vo.r & r.Ar & r.vo & التفاعل السياسي \\
\hline r..00 & $1 . \varepsilon$ & r.0 & المكافاة \\
\hline 9.89 & $\cdot . \varepsilon$ & \&.r & التنظيم \\
\hline Y. $\leqslant \varepsilon$ & .1 & $\varepsilon .1$ & التوجيه \\
\hline V.or &.$r r$ & \&. Yo & الاتصال السياسي \\
\hline & $.0 r$ & r.91 & الولاء للاولة \\
\hline
\end{tabular}

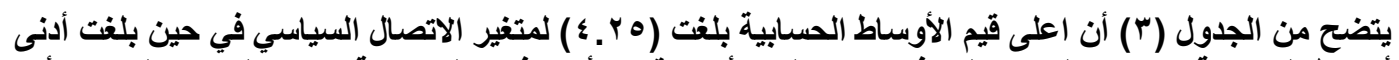

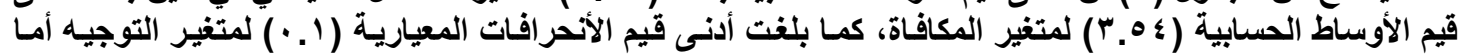

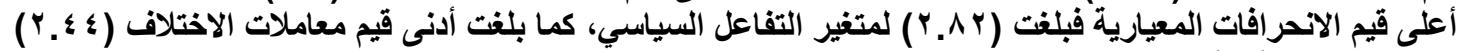

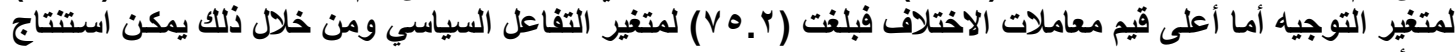

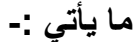

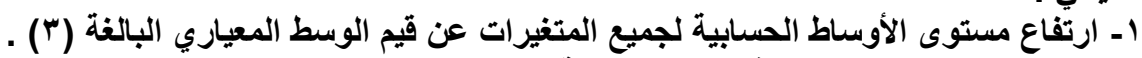

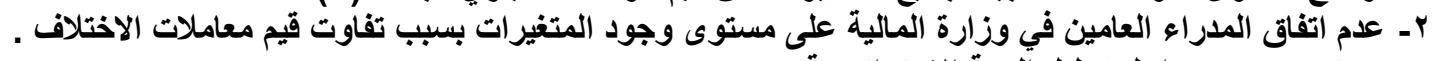

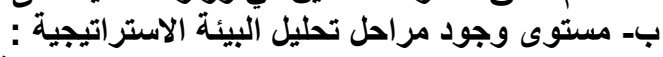
يمكن توضيح وجود مستوى متغير مراحل تحليل البيئة الاستراتيجية في وزارة المالية من خلال جدول (؛ ).

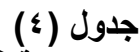

مستوى وجود بعدي تحليل البيئة الاستر اتيجية في مؤسسات وزارة المالية العراقية

\begin{tabular}{|c|c|c|c|}
\hline معامل الاختلاف & الانحراف المعياري & الوسط الحسابي & مراحل تحليل البيئة الاستراتيجية \\
\hline IT. $\leqslant V$ &. .57 & $r .79$ & التحليل الاستراتيجي الداخلي \\
\hline rv. II & $1 . r 1$ & r.or & التحليل الاستراتيجي الخارجي \\
\hline
\end{tabular}

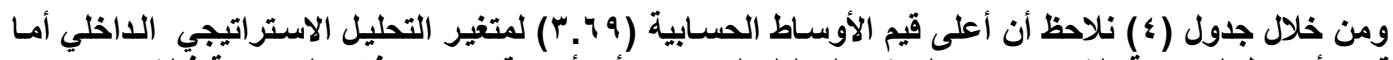

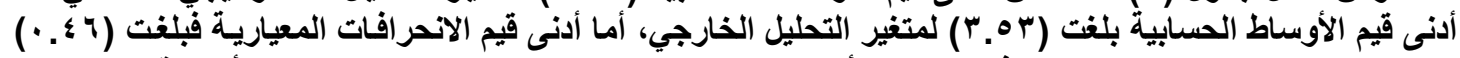

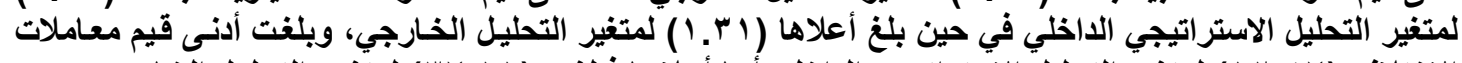

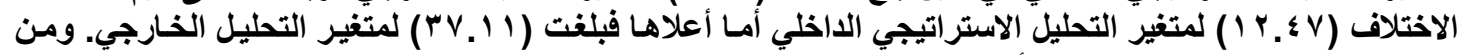

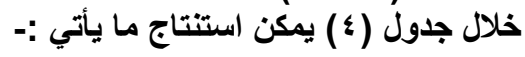




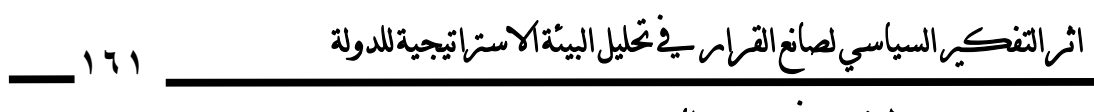

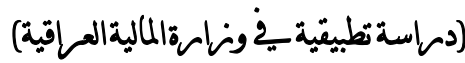

اـ ارتفاع مستوى جميع الوسطين الحسابيين لمتغيري تحليل البيئة الاستراتيجية عن قيمة الوسط المعياري البالغة

r- يوجد اتفاق بين المدراء العامين في وزارة الماليـة على مستوى وجود المتغيرات الفرعية لتحليل البيئة

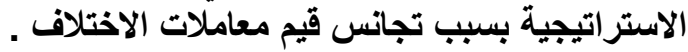

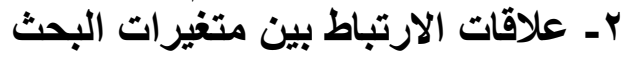

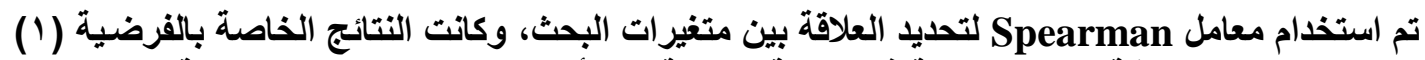

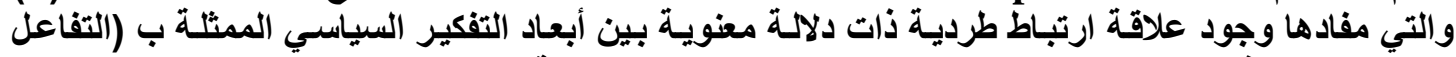

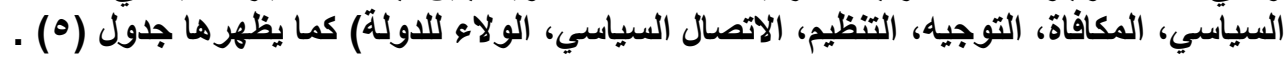

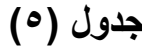

معامل ارتباط Spearman لإيجاد العلاقة بين أبعاد التفكير السياسي و تحليل البيئة الاستراتيجية

\begin{tabular}{|c|c|c|}
\hline التحليل الاستراتيجي الخارجي & التحليل الاستراتيجي الداخلي & أبعاد التفكير السياسي مراحل تحليل البيئة الاستراتيجية \\
\hline. $.470 *$ & $.090 *$ & التفاعل السياسي \\
\hline • r. & $-\cdot . \cdot \leqslant r$ & المكافاة \\
\hline . & . & التنظيم \\
\hline. .94 &.$A_{1}$ & التوجيه \\
\hline $.071 *$ &..$\leqslant \leqslant 1 *$ & الولاء للاولة \\
\hline
\end{tabular}

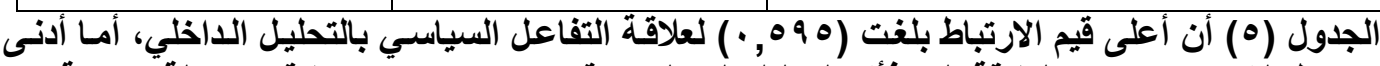

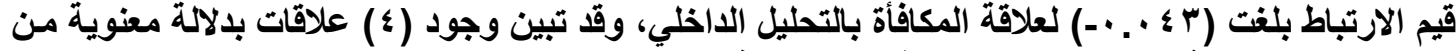

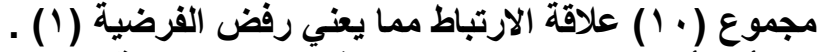

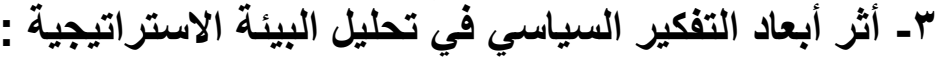

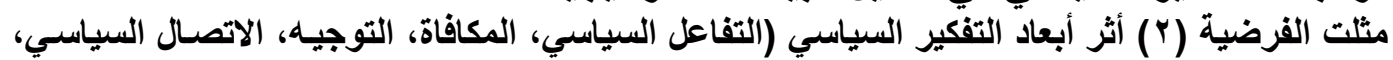

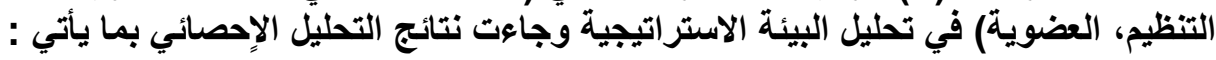




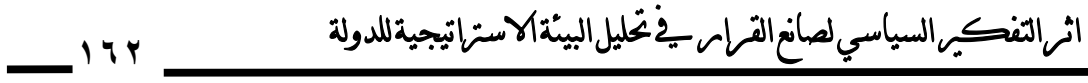 \\ (دمراسة تطبيقة فُوناسةالماليةالعـاقية)}

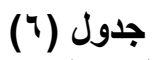

معامل الاتحدار الخطي البسيط لأبعاد التفكير السياسي في مراحل تحليل البيئة الاستراتيجية

\begin{tabular}{|c|c|c|}
\hline التحليل الاستراتيجي الخارجي & التحليل الاستراتيجي الداخلي & لـل تحليــل البيــــة \\
\hline$\cdot .791$ &..$\leqslant \wedge$.* & التفاعل السياسي \\
\hline$\cdot r \mid r$ &..$- r \Lambda$ & المكافاة \\
\hline..$\wedge r q *$ & $1.9 *$ & الاتصال السياسي \\
\hline$\cdot . \varepsilon r *$ & $\therefore \leqslant 9$. & التنظيم \\
\hline$\because .1 \leq 1$ &. $.1 \mathrm{rV}$ & التوجيه \\
\hline..$\vee V 7$ &. .90 & الولاء للاولة \\
\hline
\end{tabular}

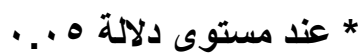

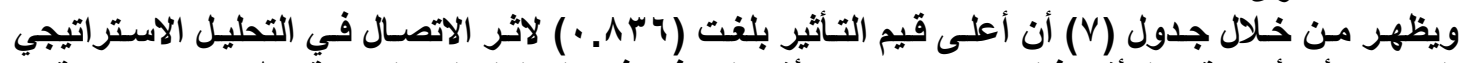

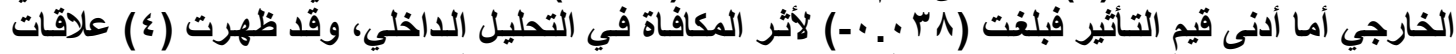

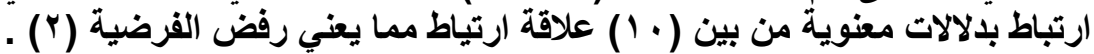

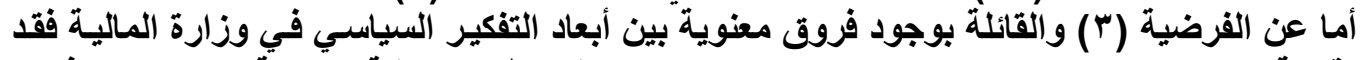

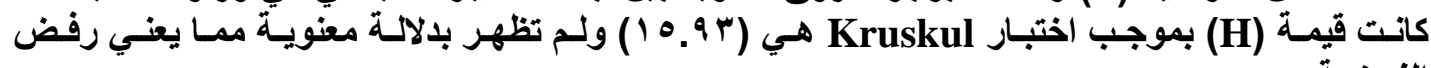

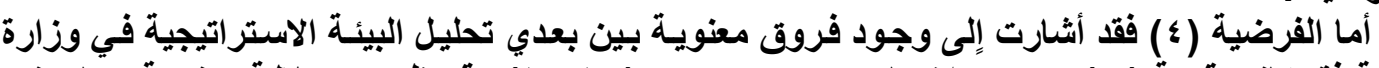
الفرضية . أنربة

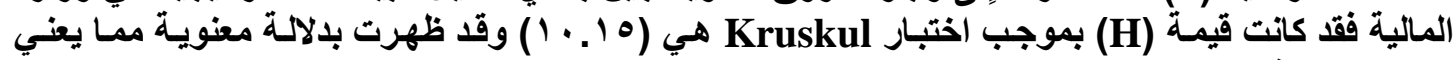
قبول الفرضية . 
(دمراسة تطبيقة فُوناسةالماليةالعـاقية)

الاستنتاجات والتوصيات

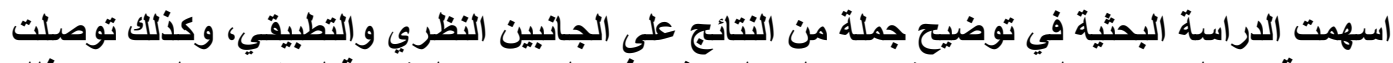

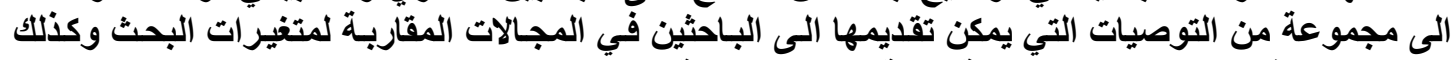

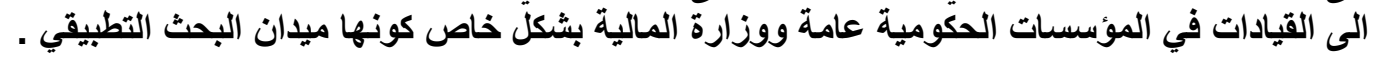

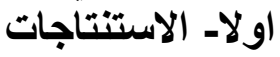

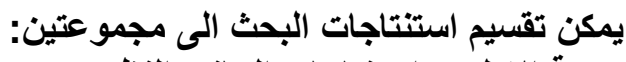

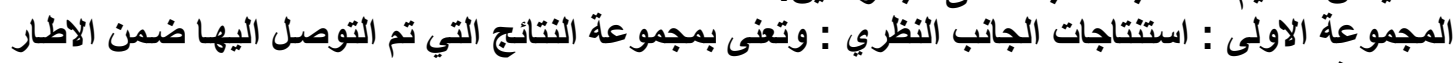

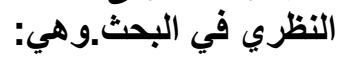

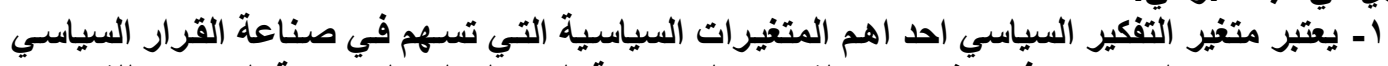

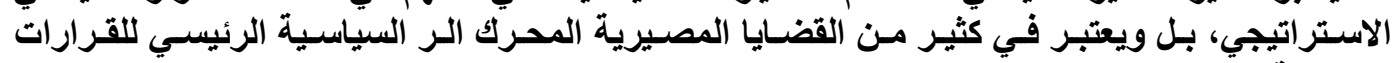
السياسية.

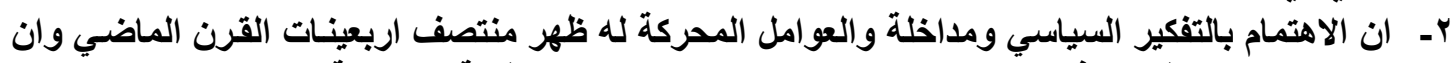

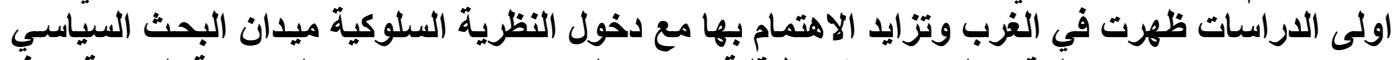

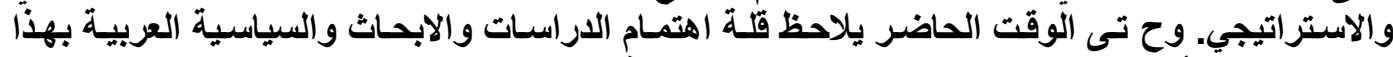

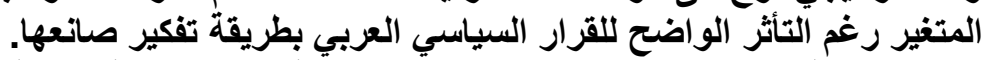

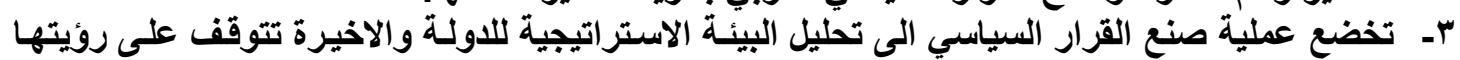

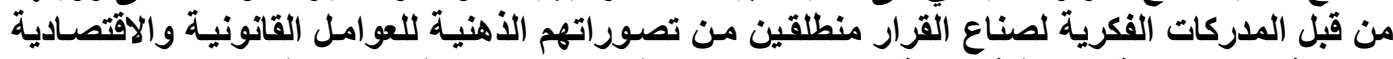

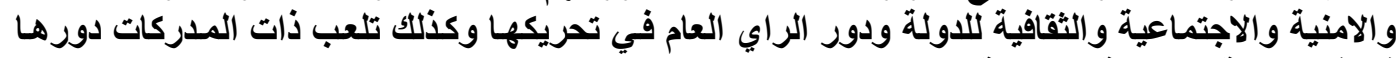

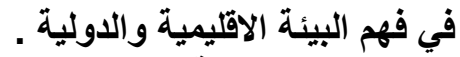

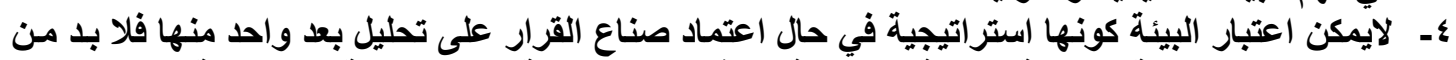

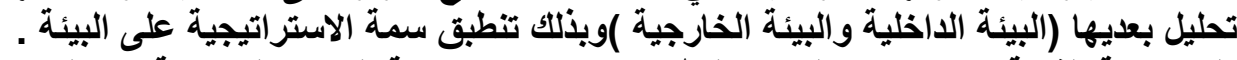

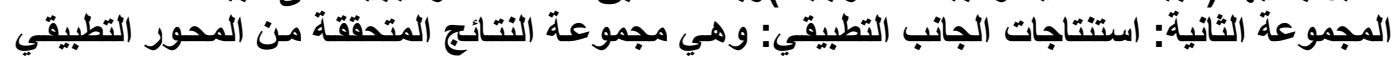
في البحث وهي:

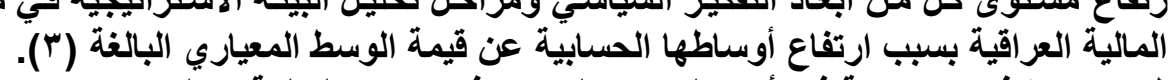

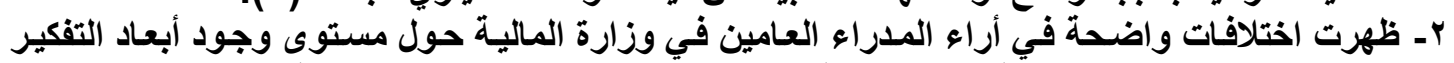

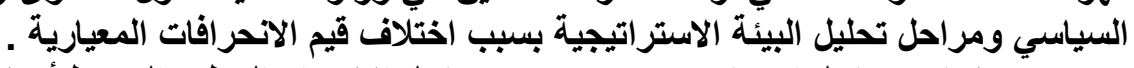

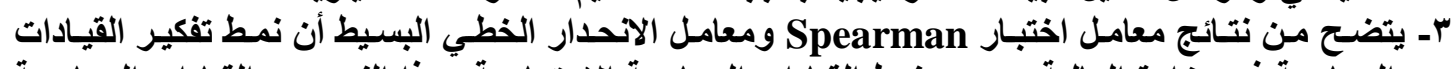

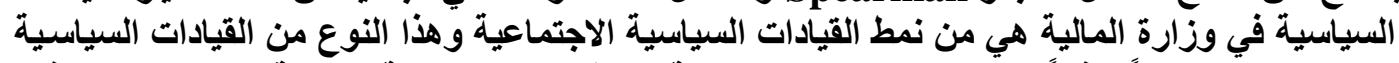

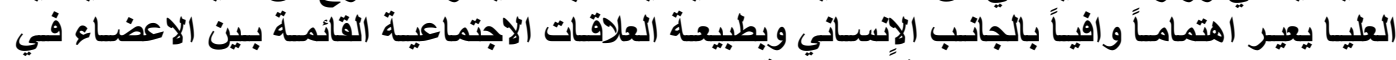

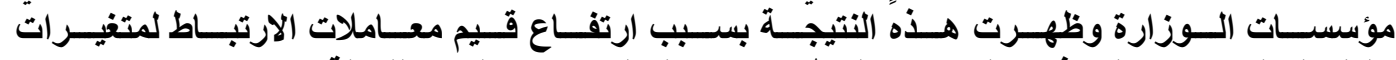

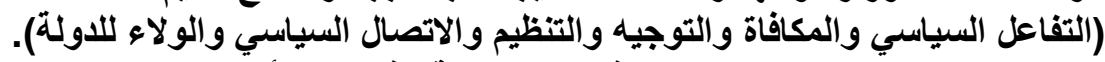

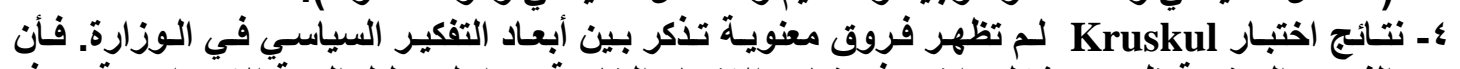

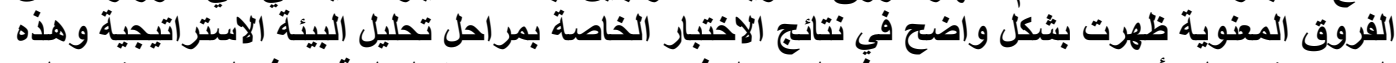

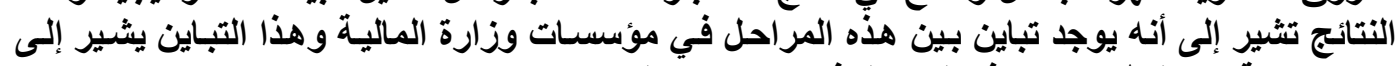

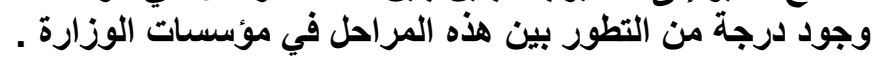


تتطلب عمليات تطوير التفكير السياسي وتحليل البيئة الاستراتيجية للاولة جملة من الخطوات الذكية التي

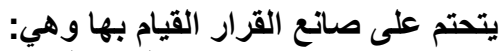

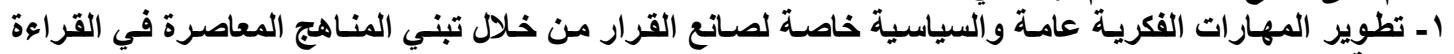

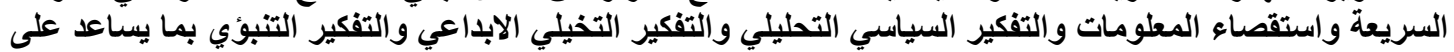

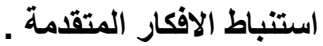

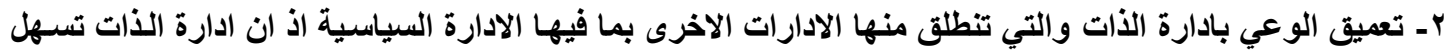

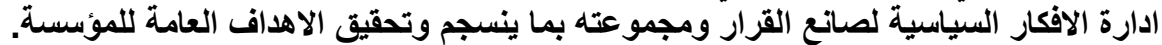

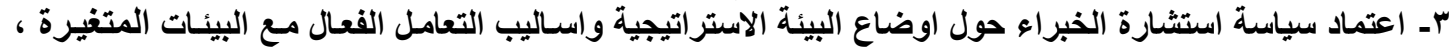
وضبط حالة عدم الاستقرار للبيئة الداخلية للمؤسسة.

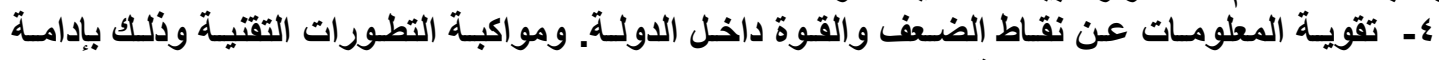

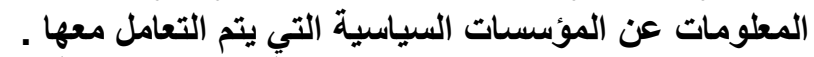

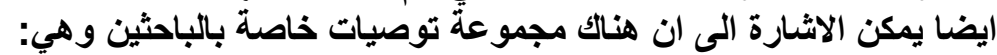

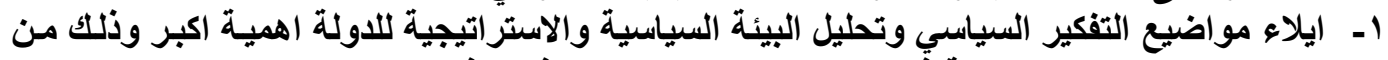

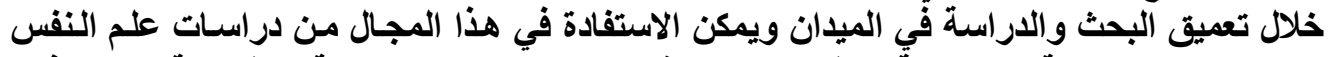

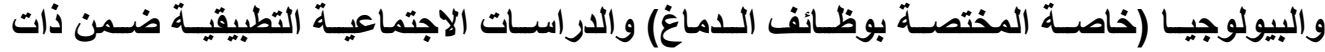

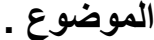
r- يمكن اقتراح مجموعة من المتغيرات المختصـة بالموضوع وذات علاقة مباشرة بتحليل خصائص

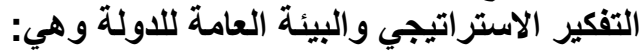

- - -

المصادر باللغة العربية

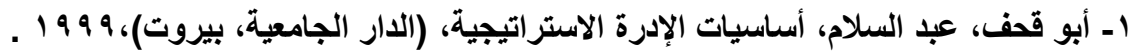

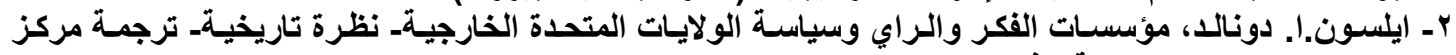

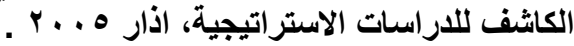
r- برو، فيليب، علم الاجتماع السياسي، ترجمة محمد عرب صاصيلا، (بيروت، الدولة الجامعية للاراسـات والنثر

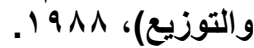

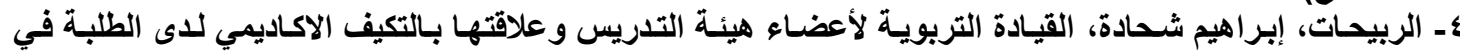

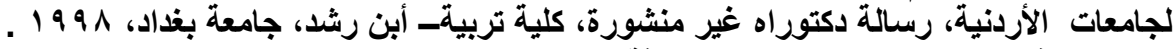

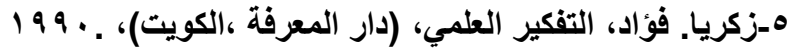

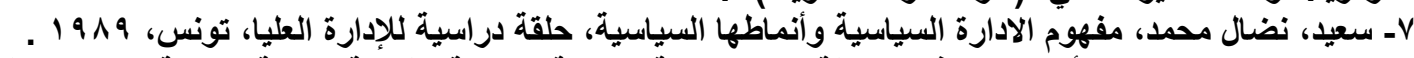

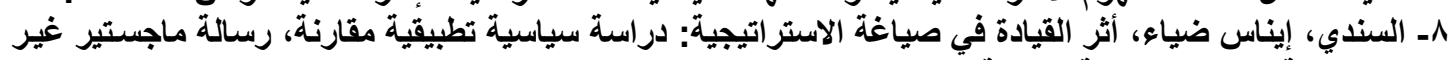

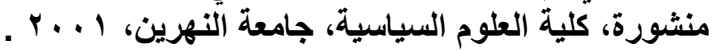

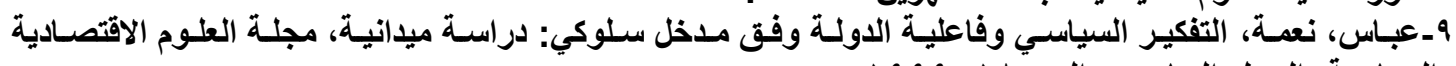

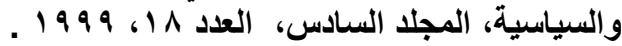

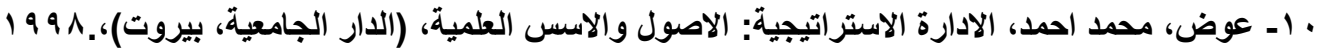

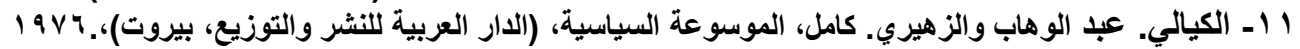

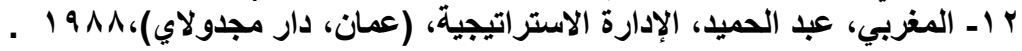


1. Fiedler, E.F , A theory of Leadership Effectiveness, (U.S.A, Mc Graw Hill ) 1967.

2. Hoffer, C.W. \& Schendel, S.D., Strategy Formulation : Analytical concept, , West Publishing,U.S.A ), 1978.

3-. Stogdill , R.M , Hand book of Leadership : A survey of Theory and Research , (Free Press,U.S.A ), 1974.

4. Sharplin, A, Stragtegic Management, (, Mc Graw Hill, U.S.A ), 1985.

5. Norayanan, V.K \& Faha, L, The Micro-Politics of Strategy Formulation, Academy of Management Review, U.S.A, Vol. 7, N.1, 1982.

6- Yukel, G.A, Learedship in Organization, (U.S.A, Printice Hill), 1989. 